\title{
Effects of knowledge management on innovation capabilities amongst small and medium enterprises in South Africa: The case of Buffalo City Metropolitan Municipality
}

\begin{tabular}{|c|c|}
\hline \multicolumn{2}{|c|}{$\begin{array}{l}\text { Authors: } \\
\text { Courage Gwena }^{1} \text { (1) } \\
{\text { Willie T. Chinyamurindi }{ }^{1}}^{\text {(1) }}\end{array}$} \\
\hline \multicolumn{2}{|c|}{$\begin{array}{l}\text { Affiliations: } \\
\text { 'Department of Business } \\
\text { Management, Faculty of } \\
\text { Management and Commerce, } \\
\text { University of Fort Hare, } \\
\text { South Africa }\end{array}$} \\
\hline \multicolumn{2}{|c|}{$\begin{array}{l}\text { Corresponding author: } \\
\text { Willie Chinyamurindi, } \\
\text { wchinyamurindi@ufh.ac.za }\end{array}$} \\
\hline \multicolumn{2}{|c|}{$\begin{array}{l}\text { Dates: } \\
\text { Received: } 11 \text { Feb. } 2018 \\
\text { Accepted: } 16 \text { Oct. } 2018 \\
\text { Published: } 28 \text { Nov. } 2018\end{array}$} \\
\hline \multicolumn{2}{|c|}{$\begin{array}{l}\text { How to cite this article: } \\
\text { Gwena, C. \& Chinyamurindi, } \\
\text { W.T., 2018, 'Effects of } \\
\text { knowledge management on } \\
\text { innovation capabilities } \\
\text { amongst small and medium } \\
\text { enterprises in South Africa: } \\
\text { The case of Buffalo City } \\
\text { Metropolitan Municipality', } \\
\text { Southern African Journal of } \\
\text { Entrepreneurship and Small } \\
\text { Business Management 10(1), } \\
\text { a177. https://doi.org/10.4102/ } \\
\text { sajesbm.v10i1.177 }\end{array}$} \\
\hline \multicolumn{2}{|c|}{$\begin{array}{l}\text { Copyright: } \\
\text { ( ) 2018. The Authors. } \\
\text { Licensee: AOSIS. This } \\
\text { is licensed under the } \\
\text { Creative Commons } \\
\text { Attribution License. }\end{array}$} \\
\hline \multicolumn{2}{|l|}{ Read online: } \\
\hline 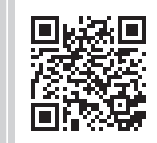 & $\begin{array}{l}\text { Scan this QR } \\
\text { code with your } \\
\text { smart phone or } \\
\text { mobile device } \\
\text { to read online. }\end{array}$ \\
\hline
\end{tabular}

Background: South Africa is witnessing a growth in small and medium enterprises (SMEs). Given this rise in SMEs, there is a need to pay attention to those factors that influence how these enterprises perform.

Aim: The purpose of the study was to investigate the effects of knowledge management (KM) on innovation capabilities (IC) in SMEs with a special focus on Buffalo City Metropolitan Municipality.

Setting: This study is the first to investigate the effects of KM on IC in SMEs operating in South Africa. Given the scarcity of studies on KM in SMEs in the sub-Saharan region, this study contributes to the literature on the effects of KM on IC.

Method: A quantitative research approach was followed in carrying out this study. Descriptive and inferential statistics were performed to answer the research questions and test the hypotheses of the study. The respondents $(n=280)$ were SME representatives operating in the Buffalo City Metropolitan Municipality.

Results: Knowledge management is found to exert a positive effect on SMEs' IC.

Conclusion: Findings from the study can assist various practitioners, directly or indirectly involved with development of business, to develop strategies that improve SMEs' growth and sustainability. These practitioners include strategic management researchers, policymakers, SME owners and managers and lecturers.

\section{Introduction}

\section{Background}

Small and medium enterprises (SMEs) are becoming an increasingly influential factor behind economic growth across the world (Comeig, Fernández-Blanco \& Ramírez 2015). It is assumed that this is a result of the SMEs' capacity to invent new products and services, generate large volumes of goods, increase exports, develop entrepreneurship skills and solve unemployment problems (Khan, Awang \& Zulkifli 2013). As a result, the South African government in 2014 created the Ministry of Small Business Development with the aim of supporting SMEs, maintaining and promoting growth and sustainability in small business (Maziti, Chinyamurindi \& Marange 2018).

However, regardless of the support mechanisms put in place by the South African government to promote and maintain small business growth, statistics indicate that $50 \%$ of SMEs in South Africa fail within 24 months of their establishment (Govender \& Mtembu 2015). It has been discovered that to attain success and organisational growth, SMEs must sustain and create a stable base of knowledge resources. This necessitates instituting of knowledge management (KM) as a strategic move (Teece, Pisano \& Shuen 1997). Strategic management practitioners and academics agree on the view that knowledge has become the epicentre of new opportunities (Barnes 2015).

Knowledge management focuses on locating and creating knowledge, ensuring its flow and eventual utilisation for the realisation of organisational long-term goals (Valdez-Juárez, GarcíaPérez \& Maldonado-Guzmán 2016). In addition, KM practices such as knowledge acquisition (KA) (the process of obtaining knowledge from within and outside an organisation) (Ha, Lo \& Wang 2016) and knowledge sharing (KS) (transfer of information amongst employees and departments within 
an organisation) are credited with enhancing innovation capabilities (IC) of an enterprise (Sulistiyani \& Harwick 2016). We define KM as a process by which a firm acquires knowledge from external sources through such activities as collaborations, hiring new employees and joining professional networking platforms. The acquired knowledge is then shared amongst employees within the firm to improve its IC. In investigating $\mathrm{KM}$, the research also considered absorptive capacity (AC) as a 'catalyst' of how KM improves enterprises' IC, referring to organisations' dynamic capabilities that enable them to develop new products, processes and services (Altuntas, Dereli \& Kusiak 2016). In this study, IC is defined as a firm's ability to develop new products and services, leadership processes based on knowledge acquired from external sources and shared with an organisation. Cohen and Levinthal (1990:128) defined AC as the 'ability to recognise the value of new external information, assimilate it, and apply it to commercial ends'.

Existing literature also shows that researchers and policy developers of the 21st century view $\mathrm{KM}$ as the panacea to the challenge of SME failure (Zheng et al. 2011; Zhou \& Li 2012). Interestingly, it has emerged that studies that examine effects of KM from the SME dimension, especially in developing countries, are limited and those available provide fragmented insights (e.g. Dursty \& Edvardsson 2012; Dwivedi et al. 2011; Ribiere \& Christian 2013). Above that, Wang and Yang (2016) noted that KM studies have been concentrated on large corporations only as opposed to SMEs.

This study explores the effects of KM on IC in SMEs. The focus is put on the two dimensions of KM, namely KA and KS, and their effects on IC and AC. This study also investigated the effects of AC on IC in SMEs. In South Africa, an SME is defined by the National Small Business Act of 2003 and 2004 as:

... a separate and distinct business entity, including co-operative enterprises and non-governmental organisations, managed by one or more owners which, including its branches or subsidiaries, if any, is predominantly carried out in any sector or sub-sector of the South African economy. (Republic of South Africa 2004:3)

\section{Literature review}

Existing literature was reviewed on the interaction and relationship between the constructs under investigation in this research. The literature reviewed includes publications on the link and connection between $\mathrm{KM}$ and $\mathrm{AC}, \mathrm{AC}$ and IC, $\mathrm{KM}$ and IC. The reviewed literature assists in formulation of the study's research hypotheses. The literature attempts to provide a secondary answer to the main research question, which reads as follows: What are the effects of AC and KM on IC of SMEs in South Africa?

\section{Knowledge management and absorptive capacity}

According to Wang and Yang (2016), a firm's AC is reliant on available knowledge within an enterprise. Hung and Chen (2010) sustain that AC is maintained as an end product of continuous acquisition and application of new knowledge within a firm. Generated knowledge should be shared with all employees through either a formal or informal network to improve understanding and creativity (Abdallah, Khalil \& Divine 2012).

It is also argued that effective information sharing within an enterprise determines the level of its AC (Suppiah \& Sandhu 2011). A sound AC allows a firm to process, understand, analyse and interpret information and knowledge acquired from external sources (Jeon, Kim \& Koh 2011). In an empirical study conducted in Taiwan to investigate the achievements of KM in SMEs, Wang and Yang (2016) suggested that SMEs should absorb knowledge from external sources so that they can leverage it to solve their problems and exploit new opportunities.

In this study, it is proposed that $\mathrm{AC}$ is a critical factor that enhances the effects of $\mathrm{KM}$ on firms' innovative capabilities. Knowledge management and AC have the same intention, which is to improve sustainability and performance (Nowacki \& Bachnik 2016). However, KM practices instituted by an organisation have an impact on its ability to assimilate information shared from within and acquired from external sources (Suh, You \& Kim 2013). Based on all that has been discussed, it can be hypothesised that:

H1a: KA has a positive effect on SMEs' AC.

H1b: KS has a positive effect on SMEs' AC.

\section{Absorptive capacity and innovation capabilities}

Absorptive capacity is the underlying mediating factor responsible for determining how much information a firm can assimilate and then convert to commercial use (Stock \& Greis 2010). Furthermore, existing studies underscore the importance of AC in an understanding of tacit knowledge acquired from external sources (Nonaka 1994; Polanyi 1957). It is assumed that high levels of AC help an enterprise to comprehend tacit and explicit knowledge, making it the decisive basis on which innovative capabilities are enriched, resulting in the development of diverse products, markets, processes and systems (Arpaci 2017).

Similarly, Colombo, Foss and Rosso-Lamastra (2012) concluded that SMEs' capacity to innovate increases if available knowledge is accompanied by a sound AC. Additionally, Lee and Lan (2011) noted that enterprises that employ people with higher levels of training and experience are likely to have greater levels of AC and enhanced innovative capabilities. Hence, based on what has been discussed it can be hypothesised that:

H2: AC has a positive effect on SMEs' IC.

\section{Knowledge management and innovation capabilities}

The link between KM and IC is that of input and an output, respectively (Chiu \& Fogel 2014). Santoro et al. (2017) 


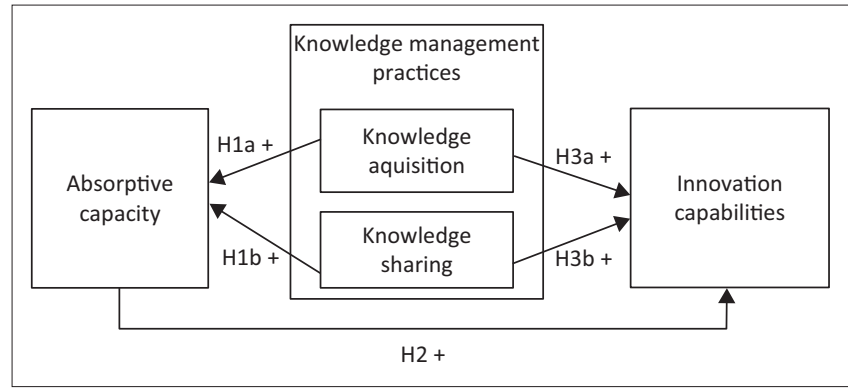

FIGURE 1: Research model.

discovered that knowledge is the key component of an enterprise's innovative behaviour and capabilities. The first step in the relationship is acquiring knowledge from outside sources and sharing it internally; that knowledge is subsequently transformed into a basis from which diverse and new opportunities, products and services, processes and markets are developed. Javernick-Will (2013) found that KA exerts a positive impact on IC, but Moustaghfir and Schiuma (2013) argue that KA is indirectly influenced by IC. According to Sohrabi and Mirali (2014), platforms and mechanisms that facilitate acquisition and sharing of knowledge should be put in place to enhance learning and improve innovation abilities.

Knowledge management is designed to convert individual knowledge (tacit knowledge) to organisational knowledge through sharing, which is then utilised to enhance an enterprise's ability to attain its strategic objectives (Sigala \& Chalkiti 2015). Explicit knowledge such as market research, market analysis and prediction reports enable a firm to react to expected and unexpected changes in the business environment using its innovative capabilities (Sohrabi \& Mirali 2014).

In light of the assertion by Mezghani, Exposito and Dria (2016) that KM precedes a firm's IC, it is conceptually proposed that the two KM practices (KA and KS) will positively trigger and affect innovation abilities. Based on all that has been discussed, it can be hypothesised that:

H3a: KA has a positive effect on SMEs' IC.

H3b: KS has a positive effect on SMEs' IC.

Figure 1 shows a model illustrating the proposed relationship amongst KM dimensions, AC and IC. Knowledge acquisition and $\mathrm{KS}$ are $\mathrm{KM}$ dimensions that will be measured in this study.

\section{Research methodology and design}

A quantitative approach was used because of its strength and merits with regards to numerically measuring relationships between different constructs (Wiid \& Diggines 2013). Quantitative researches are also a reliable and effective way of determining the nature of relationships amongst variables as opposed to the qualitative approach (Wiid \& Diggines 2013). A cross-sectional research design was used because the study involved carrying out a once-off survey on SMEs operating in the Buffalo City Metropolitan Municipality.
TABLE 1: Reliability analysis.

\begin{tabular}{lccc}
\hline Variables & Valid $\boldsymbol{N}$ & Items used & Cronbach's $\boldsymbol{\alpha}$ \\
\hline KS & 280 & 10 & $0.906^{*}$ \\
KA & 280 & 7 & $0.836^{*}$ \\
AC & 280 & 10 & $0.836^{*}$ \\
IC & 280 & 13 & $0.892^{*}$ \\
\hline KS, knowledge sharing; KA, knowledge acquisition; AC, absorptive capacity; IC, innovation \\
$\begin{array}{l}\text { capabilities; } \alpha \text {, alpha. } \\
\text { *, Significantly acceptable reliability. }\end{array}$
\end{tabular}

\section{Sampling and data collection}

Data was gathered from 280 SME representatives in the capacity of either a manager or owner. The participants were drawn from start-ups operating in various sectors such as retail, agriculture, wholesale, services and manufacturing. The start-ups from which the participants were drawn from should have existed for a period of 1-10 years. A questionnaire was administered to SME managers and owners, and the researcher obtained informed consent before the respondents were handed the questionnaire for completion. After respondents were done with answering the questions on the questionnaire, they were subsequently collected for analysis. The decision to collect data from SMEs in Buffalo City Metropolitan Municipality was based on convenience and accessibility factors to the researcher.

\section{Measures}

The instrument used in this study includes scales adopted from other studies, (Abdallah et al. 2012; Lee et al. 2016; Liao Fei \& Chen 2006). The questionnaire contains seven demographic questions and four measurement scales adding up to 40 items. Respondents gave responses to measurement scales on a five-point Likert scale by circling the appropriate response.

\section{Reliability and validity}

The coefficient alpha, developed by Cronbach (1951), is the most commonly used index for estimating the reliability of measurement instruments such as scales, multiple item tests and questionnaires. Following are the results for the internal consistency of the data collection instrument. Table 1 shows the reliability of each scale as it relates to the variable measured. The Cronbach's alpha for the scales ranged from 0.836 to 0.906 , which showed high-reliability coefficients for the study constructs.

\section{Ethical consideration}

This research study adhered to standard ethical considerations that should be observed by researchers within the university. To ensure this, the researcher applied for and obtained an ethical clearance from the university's ethics committee. Anonymity, confidentiality and the right to withdraw from the study if they felt like doing so, were guaranteed to the respondents. In addition, permission and informed consent were sought from start-ups to administer the survey questionnaire to the managers in cases where the business owners were not available. 


\section{Data analysis and results}

Data collected was analysed using the Statistical Package for Social Sciences version 24. All tests were carried out at the 5\% level of significance. A descriptive analysis was used to describe the study's demographic features. Graphical illustrations are presented in the form of tables and bar charts.

\section{Demographic profile of the respondents}

Before detailed data analysis commenced, basic distributions according to gender, ethnicity, age, educational level, industry category, age of firm and firm's capital size were initially performed. A descriptive approach was used to describe the demographic variables of the study (see Table 2).

\section{Hypothesis testing}

From the three hypothesised frameworks the results of the correlational analysis indicate that a statistically significant correlation exists between all of the study variables. It is therefore imperative to use simple linear regression models to test these hypothesised frameworks. The Durbin-Watson test for auto-correlation was used, and to test the assumption of homoscedasticity and normality of residuals, special plots

TABLE 2: Descriptive statistics for biographical variables $(N=280)$.

\begin{tabular}{|c|c|c|c|c|}
\hline Variable & Levels & $d f$ & $f$ & Valid \% \\
\hline \multirow[t]{2}{*}{ Gender } & Male & 1 & 159 & 56.8 \\
\hline & Female & - & 121 & 43.2 \\
\hline \multirow[t]{5}{*}{ Ethnicity } & Black people & 4 & 185 & 66.1 \\
\hline & Mixed-race people & - & 34 & 12.1 \\
\hline & White people & - & 38 & 13.6 \\
\hline & Indian people & - & 20 & 7.1 \\
\hline & Other & - & 3 & 1.1 \\
\hline \multirow[t]{5}{*}{ Age } & Below 20 years & 4 & 12 & 4.3 \\
\hline & $20-30$ years & - & 60 & 21.4 \\
\hline & $31-40$ years & - & 79 & 28.2 \\
\hline & $41-50$ years & - & 72 & 25.7 \\
\hline & Above 50 years & - & 57 & 20.4 \\
\hline \multirow{5}{*}{$\begin{array}{l}\text { Educational } \\
\text { level }\end{array}$} & Below matric & 4 & 2 & 0.7 \\
\hline & Matric & - & 76 & 27.1 \\
\hline & Certificate & - & 48 & 17.1 \\
\hline & Diploma or degree & - & 103 & 36.8 \\
\hline & Post-grad & - & 51 & 18.2 \\
\hline \multirow[t]{6}{*}{ Industry category } & Manufacturing & 5 & 32 & 11.4 \\
\hline & Wholesaling & - & 23 & 8.2 \\
\hline & Construction & - & 23 & 8.2 \\
\hline & Agriculture & - & 32 & 11.4 \\
\hline & Service & - & 63 & 22.5 \\
\hline & Other & - & 107 & 38.2 \\
\hline \multirow[t]{4}{*}{ Age of firm } & Below 1 year & 3 & 11 & 3.9 \\
\hline & $1-3$ years & - & 51 & 18.2 \\
\hline & $4-6$ years & - & 75 & 26.8 \\
\hline & 7 years and more & - & 143 & 51.1 \\
\hline \multirow{4}{*}{$\begin{array}{l}\text { Firm capital size } \\
\text { (in ZAR) }\end{array}$} & Less than 10000 & 3 & 32 & 11.4 \\
\hline & $10000-50000$ & - & 93 & 33.2 \\
\hline & $51000-100000$ & - & 53 & 18.9 \\
\hline & More than 100000 & - & 102 & 36.4 \\
\hline
\end{tabular}

ZAR, South African rand; $d f$, degrees of freedom.
(Q-Q plots) were used. Results of the simple linear regression models are presented in Table 3.

To determine whether KA exerts a positive effect on SMEs' AC, a simple linear regression model was examined. Knowledge acquisition was modelled as an explanatory or independent variable and this resulted in a significant model $(F=148.379 ; p=0.000)$. The model fit and model summary statistics are presented in Table 3. In this model, KA explained a significant amount of the variance in SMEs' AC $\left(R^{2}=0.243\right.$, adjusted $\left.R^{2}=0.346\right)$. The DurbinWatson value, $d=1.456$, is between the two critical values of $1.5<d<2.5$ and therefore it may be assumed that there is no first order linear auto-correlation in the linear regression data.

Table 4 shows that the parameter estimates of the resultant model - both the constant term $\left(\beta_{0}=1.638 ; t=9.036 ; p=0.000\right)$ and the main effect of KA $\left(\beta_{1}=0.550 ; t=12.181 ; p=0.000\right)-$ are all statistically significant. Because the $\beta_{1}$ coefficient is significant, there is sufficient evidence at the $5 \%$ level of significance to conclude that KA does exert a positive effect on SMEs' AC. Thus, the resultant unstandardised regression equation is as follows (Equation 1):

SMEs $^{\prime} A C=1.638+0.550 * K A+$ residual $\varepsilon$

[Eqn 1]

Concerning Hypothesis 1b, KS was modelled as an independent variable on SMEs' AC in order to determine if there exists any statistically significant positive effect on SMEs' AC. Table 5 shows the simple linear regression model

TABLE 3: Simple linear regression model fit and summary for knowledge acquisition on small and medium enterprises' absorptive capacity.

\begin{tabular}{|c|c|c|c|c|c|c|c|}
\hline Source & Function & $d f$ & $\begin{array}{l}\text { Sum of } \\
\text { squares }\end{array}$ & $\begin{array}{l}\text { Mean } \\
\text { square }\end{array}$ & $\begin{array}{l}\text { True } \\
\text { values }\end{array}$ & $F$ & $\operatorname{Pr}>F$ \\
\hline \multirow{8}{*}{$\begin{array}{l}\text { Model } \\
\text { summary }\end{array}$} & Regression & 1 & 28.483 & 28.483 & - & 148.379 & $0.000 *$ \\
\hline & Residual & 278 & 53.365 & 0.192 & - & - & - \\
\hline & Total & 279 & 81.848 & - & - & - & - \\
\hline & Observations & - & - & 280 & - & - & - \\
\hline & $\begin{array}{l}R \text { (est. standard } \\
\text { error) }\end{array}$ & - & - & 0.590 & 0.43813 & - & - \\
\hline & $R^{2}$ (adjusted $R^{2}$ ) & - & - & 0.348 & 0.34600 & - & - \\
\hline & $\begin{array}{l}F \text { change (sig. } F \\
\text { change) }\end{array}$ & - & - & 148.379 & 0.00000 & - & - \\
\hline & $\begin{array}{l}\text { Durbin-Watson } \\
\text { test - test for } \\
\text { auto-correlation }\end{array}$ & - & - & 1.456 & - & - & - \\
\hline
\end{tabular}

Note: Independent variables: constant, SMEs AC; dependent variable: KA.

KA, knowledge acquisition; SME, small and medium enterprises; AC, absorptive capacity; $\mathrm{Pr}$ probability of $\mathrm{F}$ statistic; est., estimation; sig., significance; $d f$, degrees of freedom.

*, Significant fit.

TABLE 4: Parameter estimates for the knowledge acquisition of small and medium enterprises' absorptive capacity model.

\begin{tabular}{|c|c|c|c|c|c|}
\hline \multirow[t]{2}{*}{ Parameter } & \multicolumn{2}{|c|}{$\begin{array}{l}\text { Unstandardised } \\
\text { coefficients }\end{array}$} & \multirow[t]{2}{*}{$\begin{array}{l}\text { Standardised } \\
\text { coefficients }(B)\end{array}$} & \multirow[t]{2}{*}{$t$} & \multirow[t]{2}{*}{ Sig. } \\
\hline & B & SE & & & \\
\hline Constant & 1.638 & 0.181 & - & 9.036 & $0.000 *$ \\
\hline KA & 0.550 & 0.045 & 0.590 & 12.181 & $0.000 *$ \\
\hline
\end{tabular}

Note: Independent variables: constant, KA; dependent variable: SMEs' AC.

KA, knowledge acquisition; SME, small and medium enterprises; AC, absorptive capacity; SE, standard error; Sig., significance.

*, Significant fit. 
TABLE 5: Simple linear regression model fit and summary for knowledge sharing on small and me

\begin{tabular}{llcccccc}
\hline Source & Function & $d f$ & $\begin{array}{c}\text { Sum of } \\
\text { squares }\end{array}$ & $\begin{array}{c}\text { Mean } \\
\text { square }\end{array}$ & $\begin{array}{c}\text { True } \\
\text { values }\end{array}$ & $\boldsymbol{F}$ & Pr>F \\
\hline Model & Regression & 1 & 15.120 & 15.120 & - & 62.991 & $0.000^{*}$ \\
summary & Residual & 278 & 66.728 & 0.240 & - & - & - \\
& Total & 279 & 81.848 & - & - & - & - \\
& Observations & - & - & 280 & - & - & - \\
& $R$ (est. standard & - & - & 0.430 & 0.48993 & - & - \\
& $\begin{array}{l}\text { error) } \\
\left.R^{2} \text { (adjusted } R^{2}\right)\end{array}$ & - & - & 0.185 & 0.18200 & - & - \\
& $\begin{array}{l}F \text { change (sig. } F \\
\text { change) }\end{array}$ & - & - & 62.991 & 0.00000 & - & - \\
& $\begin{array}{l}\text { Durbin-Watson } \\
\text { test - test for } \\
\text { auto-correlation }\end{array}$ & - & - & 1.487 & - & - & - \\
\hline
\end{tabular}

Note: Independent variables: constant, KS; dependent variable: SMEs' AC.

KA, knowledge acquisition; SME, small and medium enterprises; AC, absorptive capacity; $\mathrm{Pr}$, probability of $\mathrm{F}$ statistic; est., estimation; sig., significance; $d f$, degrees of freedom.

*, Significant fit.

TABLE 6: Parameter estimates for the knowledge sharing on small and medium enterprises' absorptive capacity model.

\begin{tabular}{lccccc}
\hline Parameter & \multicolumn{2}{c}{ Unstandardised coefficients } & $\begin{array}{c}\text { Standardised } \\
\text { coefficients (B) }\end{array}$ & $t$ & Sig. \\
\cline { 2 - 3 } & $\boldsymbol{B}$ & SE & & & \\
\hline Constant & 1.441 & 0.301 & - & 4.781 & $0.000^{*}$ \\
KS & 0.552 & 0.069 & 0.430 & 7.937 & $0.000^{*}$ \\
\hline
\end{tabular}

Note: Independent variables: constant, KS; dependent variable: SMEs' AC.

KS, knowledge sharing; SME, small and medium enterprises; AC, absorptive capacity; Sig. significance; SE, standard error.

*, Significant fit.

summary and overall fit statistics. The analysis found that the adjusted $\mathrm{R}^{2}$ of the model was 0.182 , which means that the linear regression explains only $18.2 \%$ of the variance in the dependent variable. The resultant model revealed a significant fit $(F=62.991 ; p=0.000)$. The test for auto-correlation shows that there is no first order linear auto-correlation in the data $(d=1.487)$.

The parameter estimates in Table 6 reveal that KS has a statistically significant positive effect on SMEs' AC $\left(\beta_{1}=\right.$ $0.552 ; t=7.937 ; p=0.000$ ). Thus, at the $5 \%$ level of significance the conclusion is that KS exerts a positive effect on SMEs' AC. The resultant model is as follows (Equation 2):

SMEs $^{\prime} A C=1.441+0.552 * \mathrm{KS}+$ residual $\varepsilon$

[Eqn 2]

Concerning Hypothesis 2, the test was to determine whether AC exerts a positive effect on SMEs' IC. For this, a simple linear regression model was examined. The model fit statistics in Table 7 shows that the resultant model was highly significant $(F=219.679 ; p=0.000)$. Also in the same table is the model summary statistics, which reveal that AC explains $44.1 \%$ of the variation in SMEs' IC $\left(R^{2}=0.441\right.$; adjusted $R^{2}=0.439$ ). The assumption is that there is no auto-correlation in the linear regression data because the Durbin-Watson test gave a statistic that is between the two critical values of $1.5<d<2.5(d=1.979)$.

Parameter estimates (Table 8) show that both the constant term and AC have a statistically significant effect on SMEs' IC. The regression coefficients are $\beta_{0}=1.467(p=0.000)$ and $\beta_{1}=0.641(p=0.000)$, respectively. Because the main effect
TABLE 7: Simple linear regression model fit and summary for absorptive capacity on small and medium enterprises' innovation capabilities.

\begin{tabular}{llcccccc}
\hline Source & Function & $\boldsymbol{d f}$ & $\begin{array}{c}\text { Sum of } \\
\text { squares }\end{array}$ & $\begin{array}{c}\text { Mean } \\
\text { square }\end{array}$ & $\begin{array}{c}\text { True } \\
\text { values }\end{array}$ & $\boldsymbol{F}$ & $\mathrm{Pr}>\boldsymbol{F}$ \\
\hline Model & Regression & 1 & 33.620 & 33.620 & - & 219.679 & $0.000^{*}$ \\
& Residual & 278 & 42.545 & 0.153 & - & - & - \\
& Total & 279 & 76.165 & - & - & - & - \\
& Observations & - & - & 280 & - & - & - \\
& $\begin{array}{l}R \text { (est. standard } \\
\text { error) }\end{array}$ & - & - & 0.664 & 0.3912 & - & - \\
& $\begin{array}{l}\left.R^{2} \text { (adjusted } R^{2}\right) \\
\quad\end{array}$ & - & - & 0.441 & 0.4390 & - & - \\
& $\begin{array}{l}F \text { change }(\text { sig. } F \\
\text { change) }\end{array}$ & - & - & 219.679 & 0.0000 & - & - \\
& $\begin{array}{l}\text { Durbin-Watson } \\
\text { test - test for } \\
\text { auto-correlation }\end{array}$ & - & - & 1.979 & - & - & - \\
\hline
\end{tabular}

Note: Independent variables: constant, AC; dependent variable: SMEs' IC.

$\mathrm{KA}$, knowledge acquisition; SME, small and medium enterprises; $\mathrm{AC}$, absorptive capacity; $\mathrm{Pr}$ probability of F statistic; est., estimation; sig., significance; $d f$, degrees of freedom.

*, Significant fit.

TABLE 8: Parameter estimates for the absorptive capacity on small and medium enterprises' innovation capabilities model.

\begin{tabular}{lcccccc}
\hline Parameter & \multicolumn{2}{c}{ Unstandardised coefficients } & $\begin{array}{c}\text { Standardised } \\
\text { coefficients }(\boldsymbol{B})\end{array}$ & $\boldsymbol{t}$ & Sig \\
\cline { 2 - 6 } & $\boldsymbol{B}$ & $\mathrm{SE}$ & & - & 8.786 & $0.000^{*}$ \\
\hline Constant & 1.467 & 0.167 & 0.664 & 14.822 & $0.000^{*}$ \\
\hline AC & 0.641 & 0.043 & &
\end{tabular}

Note: Independent variables.

AC, absorptive capacity; SME, small and medium enterprises; sig, significance; SE, standard error.

*, Significant fit.

TABLE 9: Simple linear regression model fit and summary for knowledge acquisition on small and medium enterprises' innovation capabilities.

\begin{tabular}{llcccccc}
\hline Source & \multicolumn{1}{c}{ Function } & $d f$ & $\begin{array}{c}\text { Sum of } \\
\text { squares }\end{array}$ & $\begin{array}{c}\text { Mean } \\
\text { square }\end{array}$ & $\begin{array}{c}\text { True } \\
\text { values }\end{array}$ & $\boldsymbol{F}$ & Pr>F \\
\hline Model & Regression & 1 & 25.204 & 25.204 & - & 137.487 & $0.000^{*}$ \\
summary & Residual & 278 & 50.962 & 0.183 & - & - & - \\
& Total & 279 & 76.165 & - & - & - & - \\
& Observations & - & - & 280 & - & - & - \\
& $\begin{array}{l}R \text { (est. standard } \\
\text { error) }\end{array}$ & - & - & 0.575 & 0.42815 & - & - \\
& $R^{2}$ (adjusted $R^{2}$ ) & - & - & 0.331 & 0.32800 & - & - \\
& $\begin{array}{l}F \text { change (sig. } F \\
\text { change) }\end{array}$ & - & - & 137.487 & 0.00000 & - & - \\
& $\begin{array}{l}\text { Durbin-Watson } \\
\text { test - test for } \\
\text { auto-correlation }\end{array}$ & - & - & 2.005 & - & - & - \\
\hline
\end{tabular}

Note: Independent variables: constant, KA; dependent variable: SMEs' IC.

KA, knowledge acquisition; SME, small and medium enterprises; AC, absorptive capacity; $\mathrm{Pr}$ probability of $\mathrm{F}$ Statistic; est., estimation; sig., significance; $d f$, degrees of freedom.

*, Significant fit.

is positive and statistically significant the conclusion is that AC exerts a positive effect on SMEs' IC. Thus, the resultant unstandardised regression equation is as follows (Equation 3):

SMEs' $I C=1.467+0.641^{*} \mathrm{AC}+$ residual $\varepsilon$

[Eqn 3]

Concerning Hypothesis $3 \mathrm{a}$, the test was to determine whether KA exerts a positive effect on SMEs' IC. A simple linear regression model was examined. Knowledge acquisition was modelled as an explanatory variable and this resulted in a significant model $(F=137.487 ; p=0.000)$. The model fit and model summary statistics are presented in Table 9. In this model, KA explained a significant amount of the variance in SMEs' IC $\left(R^{2}=0.331\right.$, adjusted $\left.R^{2}=0.328\right)$. The DurbinWatson value, $d=2.005$, is between the two critical values 
TABLE 10: Parameter estimates for knowledge acquisition on small and medium enterprises' innovation capabilities model.

\begin{tabular}{|c|c|c|c|c|c|}
\hline \multirow[t]{2}{*}{ Parameter } & \multicolumn{2}{|c|}{ Unstandardised coefficients } & \multirow{2}{*}{$\begin{array}{l}\text { Standardised } \\
\text { coefficients }(B)\end{array}$} & \multirow[t]{2}{*}{$t$} & \multirow[t]{2}{*}{ Sig } \\
\hline & $B$ & SE & & & \\
\hline Constant & 1.861 & 0.177 & - & 10.509 & $0.000 *$ \\
\hline KA & 0.518 & 0.044 & 0.575 & 11.725 & $0.000 *$ \\
\hline
\end{tabular}

Note: Independent variables: constant, KA; dependent variable: SMEs' IC.

KA, knowledge acquisition; SME, small and medium enterprises; IC, innovation capabilities; sig, significance; SE, standard error.

*, Significant fit.

TABLE 11: Simple linear regression model fit and summary for knowledge sharing on small and medium enterprises' innovation capabilities.

\begin{tabular}{llcccccc}
\hline Source & Function & $d f$ & $\begin{array}{c}\text { Sum of } \\
\text { squares }\end{array}$ & $\begin{array}{c}\text { Mean } \\
\text { square }\end{array}$ & $\begin{array}{c}\text { True } \\
\text { values }\end{array}$ & $\boldsymbol{F}$ & Pr>F \\
\hline Model & Regression & 1 & 19.013 & 19.013 & - & 92.483 & $0.000^{*}$ \\
& Residual & 278 & 57.152 & 0.206 & - & - & - \\
& Total & 279 & 76.165 & - & - & - & - \\
& Observations & - & - & 280 & - & - & - \\
& $R$ (est. standard & - & - & 0.500 & 0.45341 & - & - \\
& error) & & & & & & \\
& $R^{2}$ (adjusted $R^{2}$ ) & - & - & 0.250 & 0.24700 & - & - \\
& $\begin{array}{l}F \text { change } \\
\text { (sig. } F \text { change) }\end{array}$ & - & - & 92.483 & 0.00000 & - & - \\
& $\begin{array}{l}\text { Durbin-Watson } \\
\text { test }- \text { test for } \\
\text { auto-correlation }\end{array}$ & - & - & 2.145 & - & - & - \\
\hline
\end{tabular}

Note: Independent variables: constant, KS; dependent variable: SMEs' IC.

KA, knowledge acquisition; SME, small and medium enterprises; AC, absorptive capacity; $\mathrm{Pr}_{\text {, }}$ probability of $\mathrm{F}$ statistic; est., estimation; sig., significance; $d f$, degrees of freedom.

*, Significant effect.

of $1.5<d<2.5$ and therefore it can be assumed that there is no first order linear auto-correlation in the linear regression data.

Table 10 shows that the parameter estimates of the resultant model are all statistically significant $\left(\beta_{0}=1.861 ; t=10.509\right.$; $p=0.000$ and $\beta_{1}=0.518 ; t=11.725 ; p=0.000$ ). Because the $\beta_{1}$ coefficient is positive, there is sufficient evidence at the $5 \%$ level of significance to conclude that KA has a statistically significant positive effect on SMEs' IC. Thus, the resultant unstandardised regression equation is as follows (Equation 4):

SMEs' $I C=1.861+0.518^{*} K A+$ residual $\varepsilon$

[Eqn 4]

Finally, concerning Hypothesis 3b, KS was modelled as an independent variable on SMEs' IC. The aim here was to determine if there exists any statistically significant positive effect between the two variables. Table 11 shows the simple linear regression model summary and overall fit statistics. The analysis revealed that the adjusted $\mathrm{R}^{2}$ of the model was 0.152 , which means that the linear regression explains $15.2 \%$ of the variance in the data. The resultant model revealed a highly significant fit $(F=92.483 ; p=0.000)$. The test for autocorrelation showed that there is no first-order linear autocorrelation in the data $(d=2.145)$.

The parameter estimates in Table 12 reveal that KS has a statistically significant positive effect on SMEs' IC $\left(\beta_{1}=0.619\right.$; $t=9.617 ; p=0.000)$. Thus, at the $5 \%$ level of significance the conclusion is that KS exerts a positive effect on SMEs' IC. The resultant simple regression model is as follows (Equation 5):

SMEs' $I C=1.246+0.619 * K S+$ residual $\varepsilon$

[Eqn 5]
TABLE 12: Parameter estimates for the knowledge sharing on small and medium enterprises' innovation capabilities model.

\begin{tabular}{lcccccc}
\hline Parameter & \multicolumn{2}{l}{ Unstandardised coefficients } & $\begin{array}{c}\text { Standardised } \\
\text { coefficients }(\boldsymbol{B})\end{array}$ & $\boldsymbol{t}$ & Sig \\
\cline { 2 - 3 } & $\boldsymbol{B}$ & SE & & - & 4.467 & $0.000^{*}$ \\
\hline Constant & 1.246 & 0.279 & 0.500 & 9.617 & $0.000^{*}$ \\
KS & 0.619 & 0.064 & & &
\end{tabular}

Note: Independent variables: constant, KS; dependent variable: SMEs' IC.

KS, knowledge sharing; SME, small and medium enterprises; IC, innovation capabilities; sig, significance; SE, standard error.

*, Significant effect.

\section{Discussion}

This section discusses the results of the present research and explores similarities or differences of the current study with previous research studies. The discussion addresses each hypothesis and also compares the present findings with those from previous studies. The overall discussion also answers the study's three research questions.

\section{Knowledge management and absorptive capacity}

The research aimed to establish the effects of KM on AC. Therefore, the first two hypotheses were formulated to test whether KA and KS had a positive effect on SMEs' AC, respectively. To be specific, the hypotheses read as follows:

H1a: KA has a positive effect on SMEs' AC.

H1b: KS has a positive effect on SMEs' AC.

\section{Knowledge acquisition and absorptive capacity}

With regard to the effect of KA on SMEs' AC, simple linear regression model analysis revealed that $\mathrm{KA}$ exerts a positive effect on SMEs' AC. The results also revealed that KA explained a significant amount of variance in SMEs' AC. These results provided sufficient evidence to reach a conclusion that KA positively influences AC in SMEs. These results corroborate findings of an investigation that was undertaken by Valentim, Lisboa and Franco (2015) in Portugal on a sample of 260 SMEs, which established that KM practices, including KA, positively impacts a firm's AC. To support these results, Hung and Chen (2010) state that AC is maintained as an end product of continuous acquisition and application of new information within a firm.

Valentim et al. (2015) state that SMEs acquire knowledge that originates from internal and external sources through AC. In a recent study, Wang and Yang (2016) concluded that SMEs that practise KM and engage in collaborations with other businesses acquire more knowledge from external stakeholders. Abdallah et al. (2012) hold that knowledge generated and acquired should be shared with all employees through either formal or informal networks, thus summarising the link between $\mathrm{KM}$ and $\mathrm{AC}$, as well as the effect of KA on AC.

In essence, this study's statistical results with regard to the effect of KS on SMEs' AC confirm findings from a majority of empirical studies carried out elsewhere (Hung \& Chen 2010; Valentim et al. 2015; Wang \& Yang 2016). As a result, in light 
of the statistical results on the effect of KA on SMEs' IC, the study concludes that KA has a positive effect on SMEs' AC. This confirms the assumption of the study that KA enhances a firm's AC.

\section{Knowledge sharing and absorptive capacity}

This research also sought to establish the effects of KA on SMEs' AC. Based on the presented statistical results, the study established that KS, that was modelled as an independent variable on SMEs' AC, exerts a statistically significant positive effect on SMEs' AC. These results were in line with arguments by Suppiah and Sandhu (2011) that effective KS within an enterprise determines the level of its AC. In addition, this result is in line with those of a study conducted by Valentim et al. (2015) in Portugal on a sample of 260 SMEs, which established that KM practices that include $\mathrm{KS}$ and acquisition positively impact a firm's AC.

McAdam et al. (2010) stated that to enhance their AC, firms should hire new, experienced experts who in turn share their expertise with other employees within the business. As a result of sharing expertise, a firm's AC is enhanced. In addition, this study also corresponds with conclusions by Shamim, Cang and Yu (2017) that AC relies on sound $\mathrm{KM}$ practices, KS included, that facilitate easy transfer and assimilation of information. Based on the statistical results, this study concludes that KS has a positive effect on SMEs' AC.

\section{Absorptive capacity and innovation capabilities}

The study objective was to investigate the effects of AC on SMEs' IC. This subsection discusses the findings and conclusions with regard to the effects of AC and IC. To determine whether AC exerts a positive effect on SMEs' IC, a simple linear regression was performed. The research established that the main effect was positive and statistically significant. Therefore, it can authoritatively be concluded that AC exerts a positive effect on SMEs' IC.

These results are in agreement with those of a study that was aimed at investigating the influence of AC on IC in business organisations (Enkel et al. 2017). Additionally, a number of previous studies have underscored the importance of AC in an understanding of tacit knowledge acquired from external sources (Nonaka 1994; Polanyi 1957), which in turn is used to come up with various innovations within an enterprise.

\section{Knowledge management and innovation capabilities}

The research also aimed to establish the effects of KM on SMEs' IC. Two hypotheses were formulated:

H3a: KA has a positive effect on SMEs' IC.

H3b: KS has a positive effect on SMEs' IC.

Each hypothesis is discussed in detail in the following.

\section{Knowledge acquisition and innovation capabilities}

The research aimed to determine the effects of KA on SMEs' IC. To achieve this objective a simple linear regression model was examined. The coefficients were found to be positive, and it was concluded that KA had a statistically significant positive effect on SMEs' IC. The results of the current study bear some resemblance to those of a previous study by Javernick-Will (2013), which revealed that KA has a positive impact on IC. Although Moustaghfir and Schiuma (2013) argue that KA is indirectly influenced by IC, this study did not investigate the reverse effect of IC on KA.

Knowledge acquisition has also been found to enable an enterprise to react to changes in the business using its innovative capabilities (Sohrabi \& Mirali 2014). For instance, acquiring knowledge about customer needs, customer tendencies and prevailing market trends, may lead to awareness and eventual development of productions that fit well in the prevailing conditions (Bojica \& Fuentes 2012). Furthermore, acquiring knowledge through hiring experts has been established to improve an enterprise's ability to innovate because only people with the relevant know-how can develop particular services and products. Unlike other studies that focused on technology as the best way to acquire knowledge that eventually leads to improved IC (Okanga 2017; Razali et al. 2017), this study did not go that far.

\section{Knowledge sharing and innovation capabilities}

The last objective of the research was to ascertain the effects of KS on SMEs' IC. Here, the study sought to investigate and establish how KS amongst employees and colleagues within an SME can affect its IC. The research hypothesised that KS has a positive effect on SMEs' IC. To establish the actual effect of KS on SMEs' IC, simple linear regression analysis was performed. It was subsequently established that KS has a statistically significant positive effect on SMEs' IC.

The results of the current study confirm the assertions made by Koloniari and Fassoulis (2017) that KS is an important component of a firm's KM that facilitates the speed and effectiveness of the IC. Another previous study that corresponds with the current one is that of Salleh et al. (2017), which identified KS as the principal determinant of increase in the innovation of various products and services. Although Salleh et al. (2017) focused on larger firms and the current study on SMEs, the effect of KS on both categories of firms remains the same - positive. Several studies have also established positive effects of KS on IC in firms of differing sizes (Mohsam \& van Brake 2014; Sigala \& Chalkiti 2015; Sohrabi \& Mirali 2014).

\section{Implications of the study}

This section unpacks and provides a discussion on the implications of the study based on empirical evidence drawn from the study's statistical results. The implications are 
presented in a way that explains how the results of this study affect theoretical dimensions of the studied phenomenon, practitioners (SME managers, owners and employees) and policymakers. In essence, this section presents and discusses theoretical, practical and policy implications of the study, as well as recommendations on what might need to be implemented to improve innovation in SMEs and their subsequent capabilities.

\section{Theoretical implications}

The most important theoretical contribution of this study is that it helped to extend knowledge and understanding of the effects of KM on SMEs' IC from a South African perspective. The findings build on existing empirical knowledge as seen in several previous studies on KM and its effects (Bojica \& Fuentes 2012; Popoola \& Fagbola 2014; Razali et al. 2017). This study broadened the frame of information in the area of KM and its influence on IC within South African SMEs. As a result, it adds more literature that dwells on KM and IC as well as further explaining how KM impacts SMEs' AC and how the AC affects SMEs' IC. Absorptive capacity has often been investigated as a mediating factor; however, this research proved that if employed as a linear variable, it has positive effects on IC.

Although previous studies noted that there is still confusion on whether there is a difference between $\mathrm{KM}$ and $\mathrm{AC}$, this study cemented the view that the two are different research variables that can have effects on each other. Specifically, the current study established that KM practices (KS and KA) positively affect IC within SMEs. This discovery answered the study's research questions. By answering the questions, this study filled in knowledge gaps that existed in the realm of KM in SMEs, specifically in the South African context and to some extent a sub-Saharan perspective.

This work also advances an understanding into a phenomenon that is not often researched outside the Western and Asian contexts. This study is one of the few that have been conducted in sub-Saharan Africa that probes and explores the effects of KM in SMEs on IC. It adds a South African SME dimension to studies on KM, which are largely concentrated outside the sub-Saharan region (Europe and Asia) and on large firms (e.g. Dursty \& Edvardsson 2012; Dwivedi et al. 2011; Ribiere \& Christian 2013; Santoro et al. 2017). Furthermore, it showed that there was statistical evidence that supports the researchers' assumption that KM has a positive effect on SMEs' IC and AC.

\section{Practical implications}

The study's findings add practically useful knowledge to the existing insights by revealing that KM practices such as KA and KS activities have a positive effect on SMEs' ability to create new products, services and processes. The results, which show that KA positively affects SMEs' IC, suggest that managers and owners should promote KA activities to improve enterprises' IC. According to Cho and Korte (2014), useful KA activities include collaborations amongst firms or with universities, employment of experts, joining formal and informal networks, attending seminars, exhibitions and participating in business incubations. This, therefore, implies that managers and SME owners need to create conducive environments where these KA activities flourish.

With regards to KS, the results of this study imply that there is need to promote $\mathrm{KS}$ robustly within an SME to enhance its IC and AC. Small and medium enterprises' management should, therefore, ensure that experts and experienced employees are encouraged to share their expertise with colleagues so as to improve the level on which a firm provides solutions to new market demands and needs. Methods through which knowledge is shared within an enterprise include activities such as mentoring, seminars, workshops, internal refresher courses or simple observations (Arpaci 2017).

To strategic management academics, the study advises that they intensively integrate the topic of KM in the university curriculum so as to equip current and prospective SME owners with adequate and appropriate KM skills. With the advent of the knowledge economy, it is only wise that academics promote research in the area of KM and provide more insights regarding its benefits to practitioners in the industry. Furthermore, it is also advisable for SME managers and owners to employ knowledge experts or introduce a department in the organisational structure that is solely responsible for improving and advancing KM practices. This will allow robust implementation of $\mathrm{KM}$ practices in the SME. The reviewed literature showed that KM has been empirically proven to be an antidote to SME failure.

\section{Limitations of the study}

According to Wiid and Diggines (2013), no research study is without constraints and challenges. This section presents and discusses challenges faced in this research study. Notable shortcomings of this research include the fact the data collection was confined to one municipality: Buffalo City Metropolitan Municipality (BCMM). Confining data collection to BCMM limits the generalisability of this study's results. Collecting data from different municipalities would have made the results more generalisable to the entire SME population in the Eastern Cape Province or South Africa at large. Secondly, the research only considered a single respondent in an organisation in the form of SME owners or managers, ignoring other members of the organisation. If the study had considered more than one respondent per organisation, the results would have clarified the information about the organisations better. Thirdly, lack of a reliable list of current SMEs operating within the BCMM implies that some possible SMEs might have been left out the study. In addition, it might have negatively affected the determination of the research sample size because the sample size of this study was calculated based on the 2016 list of SMEs operating in the BCMM. 
The fourth limitation of this research is that the instrument used to collect data is made of scales that were adapted from studies performed outside South Africa. A South Africangenerated instrument would have captured all the necessary and appropriate elements that fit the South African context of $\mathrm{KM}, \mathrm{AC}$ and IC. Lastly, this study followed the quantitative research approach only, which meant that conclusions were drawn based solely on numerical data. If the research had followed both the qualitative and quantitative data, both numerical and qualitative data would have been collected. This would have made sure that weakness of each method was covered by the strength of the other. Therefore, based on the limitations and constraints of this research, the results should be treated with caution.

\section{Recommendations for future study}

Because this study followed a quantitative approach, it is recommended that future research follow a qualitative research method to gain more insight into the effects of $\mathrm{KM}$ on IC. Furthermore, this study recommends that future studies be carried out with the main aim of developing a South African-oriented instrument in relation to this topic. This research collected data from SMEs from various sectors. Therefore, future research should focus on investigating the effects of KM on SMEs from a single sector, for example, SMEs from the manufacturing sector only. Lastly, future research should use the same independent variables versus a different dependent variable. This will help establish the importance of KM on different business objectives and goals.

\section{Conclusion}

The overall discussion of the results of this study showed that KM has a positive effect on SMEs' IC. The study noted the methodological limitation, which might limit the generalisability of this study's results. The research concluded by recommending options for further research, which included using a different research methodology. Based on the results of the study, it is recommended that South African SMEs take KM seriously if they are to successfully enhance their IC.

\section{Acknowledgements}

The authors acknowledge with gratitude the feedback from the journal and its reviewers.

\section{Competing interests}

The authors declare that they have no financial or personal relationships that may have inappropriately influenced them in writing this article.

\section{Authors' contribution}

C.G. was a master's student, with W.T.C. as supervisor. W.T.C. assisted in conceptualising the study and supporting C.G. during the course of his studies.

\section{References}

Abdallah, S., Khalil, A. \& Divine, A., 2012, 'The impact of knowledge sharing on innovation capability in United Arab Emirates organizations', International Journal of Social, Behavioral, Educational, Economic, Business and Industrial Engineering 6(12), 201-211.

Altuntas, S., Dereli, T. \& Kusiak, A., 2016, 'Computers and industrial engineering assessment of corporate innovation capability with a data-mining approach: Industrial case studies', Computers and Industrial Engineering 102, 58-68. https:// doi.org/10.1016/j.cie.2016.10.018

Arpaci, I., 2017, 'Computers in human behavior antecedents and consequences of cloud computing adoption in education to achieve knowledge management', Computers in Human Behavior 70, 382-390. https://doi.org/10.1016/j. chb.2017.01.024

Barnes, Y.L.J., 2015, 'Knowledge acquisition and product innovation flexibility in SMEs', Business Process Management Journal 21(6), 1257-1278. https://doi. org/10.1108/BPMJ-05-2014-0039

Bojica, A.M. \& Fuentes, M., 2012, 'Knowledge acquisition and corporate entrepreneurship: Insights from Spanish SMEs in the ICT sector', Journal of World Business 47(3), 397-408. https://doi.org/10.1016/j.jwb.2011.05.007

Chiu, H. \& Fogel, J., 2014, 'The impact of manager influence tactics on innovation implementation of a knowledge management system', International Journal of Innovation Science 6(4), 185-203. https://doi.org/10.1260/1757-2223.6.4.185

Cho, S.W. \& Korte, B., 2014, 'The evaluation on the three critical models of absorptive capacity: A case study on logistics company in Korea', Universal Journal of Industrial and Business Management 2(5), 119-125.

Cohen, W.M. \& Levinthal, D.A., 1990, 'Absorptive capacity: A new perspective on learning and innovation', Administrative Science Quarterly 35(1), 128-152. https://doi.org/10.2307/2393553

Colombo, M., Foss, N. \& Rossi-Lamastra, C., 2012, 'Organizational design for absorptive capacity linking individual and organizational levels', Paper presented at the DRUID 2012 on June 19 to June 21 At CBS, Copenhagen, Denmark.

Comeig, I., Fernández-Blanco, M.O. \& Ramírez, F., 2015, 'Information acquisition in SME's relationship lending and the cost of loans', Journal of Business Research 68 1650-1652. https://doi.org/10.1016/j.jbusres.2015.02.012

Cronbach, L.J., 1951, 'Coefficient alpha and the internal structure tests', Psychometrika 16(3), 297-334. https://doi.org/10.1007/BF02310555

Dursty, S. \& Edvardsson, I.R., 2012, 'Knowledge management in SMEs: A literature review', Journal of Knowledge Management 16(6), 879-903. https://doi. org/10.1108/13673271211276173

Dwivedi, Y.K., Venkitachalam, K., Sharif, A.M., Al-Karaghouli, W. \& Weerakkody, V., 2011, 'Research trends in knowledge management: Analyzing the past and predicting the future', Information Systems Management 28(1), 43-56. https:// doi.org/10.1080/10580530.2011.536112

Enkel, E., Heil, S., Hengstler, M. \& Wirth, H., 2017, 'Exploratory and exploitative innovation: To what extent do the dimensions of individual level absorptive capacity contribute?', Technovation 60, 29-38. https://doi.org/10.1016/j. technovation.2016.08.002

Govender, L.N. \& Mtembu, V.N., 2015, 'Perceptions of employers and unemployed youth on the proposed youth employment wage subsidy incentive in South Africa: A KwaZulu-Natal study', South African Journal of Human Resource Management 13(1), 653-659.

Ha, S., Lo, M. \& Wang, Y., 2016, 'Relationship between knowledge management and organizational performance: A test on SMEs in Malaysia', Procedia - Social and Behavioral Sciences 224, 184-189. https://doi.org/10.1016/j.sbspro.2016.05.438

Hung, S.W. \& Chen, C.J., 2010, 'To give or to receive? Factors influencing members' knowledge sharing and community promotion in professional virtual communities', Journal of Information Management 47(4), 226-236. https://doi. org/10.1016/j.im.2010.03.001

Javernick-Will, A., 2013, 'Local embeddedness and knowledge management strategies for project-based multi-national firms', Engineering Management Journal 25(3), for project-based multi-national firms', Engineering Managem
16-26. https://doi.org/10.1080/10429247.2013.11431979

Jeon, S., Kim, Y.G. \& Koh, J., 2011, 'An integrative model for knowledge sharing in communities-of-practice', Journal of Knowledge Management 15, 251-269. https://doi.org/10.1108/13673271111119682

Khan, N.R., Awang, M. \& Zulkifli, C.M., 2013, 'Small and medium enterprises and human resource practices in Pakistan', International Journal of Asian Social Science 3(2), 460-471.

Koloniari, M. \& Fassoulis, K., 2017, 'Knowledge management perceptions in academic libraries', The Journal of Academic Librarianship 43(2), 135-142. https://doi. org/10.1016/j.acalib.2016.11.006

Lee, M.R. \& Lan, Y.C., 2011, 'Toward a unified knowledge management mode for SMEs', Expert Systems with Applications 38(1), 729-735. https://doi. org/10.1016/j.eswa.2010.07.025

Lee, V.H., Foo, A.T.L., Leong, L.Y. \& Ooi, K.B., 2016, 'Can competitive advantage be achieved through knowledge management? A case study on SMEs', Expert Systems with Applications 65, 136-151. https://doi.org/10.1016/j.eswa.2016.08.042

Liao Fei, W. \& Chen, C., 2006, 'Knowledge sharing, absorptive capacity and innovation capability: An empirical study of Taiwan's knowledge intensive industries', Journal of Information Science 20(10), 1-20.

Maziti, L., Chinyamurindi, W.T. \& Marange, C., 2018, 'The relationship between strategic leadership, innovation performance and competitive advantage amongst a sample of small businesses in South Africa', Journal of Contemporary Management 15, 368-394. 
McAdam, R., Miller, K., McMacken, N. \& Davies, J., 2010, 'The development of absorptive capacity-based innovation in a construction SME', The Internationa Journal of Entrepreneurship and Innovation 11(3), 231-244. https://doi.org/ Journal of Entrepreneurship and

Mezghani, E., Exposito, E. \& Drira, K., 2016, 'A collaborative methodology for tacit knowledge management: Application to scientific research', Future Generation Computer Systems 54, 450-459. https://doi.org/10.1016/j.future.2015.05.007

Mohsam, F. \& van Brakel, P.A., 2014, 'Information and knowledge sharing trends of small and medium-sized enterprises in the Western Cape, South Africa Research problem', South African Journal of Information Management 13(1), 1-10.

Moustaghfir, K. \& Schiuma, G., 2013, 'Knowledge, learning, and innovation: Re- search and perspectives', Journal of Knowledge Management 17(4), 495-510. https:// doi.org/10.1108/JKM-04-2013-0141

Nonaka, I., 1994, 'A dynamic theory of organisational knowledge creation', Organisation Science 5(1), 14-37. https://doi.org/10.1287/orsc.5.1.14

Nowacki, R. \& Bachnik, K., 2016, 'Innovations within knowledge management', Journal of Business Research 69(5), 1577-1581. https://doi.org/10.1016/j. jbusres.2015.10.020

Okanga, B., 2017, 'Small- and medium-sized enterprises' knowledge management systems as edifiers of new value innovations', South African Journal of Information systems as edifiers of new value innovations', South African Journal
Management 19(1), 1-11. https://doi.org/10.4102/sajim.v19i1.786

Polanyi, K., 1957, The great transformation: The political and economic origins of our time, Beacon Press, Boston, MA.

Popoola, S.O. \& Fagbola, O.O., 2014, 'Innovation capability of managers in Nigerian large-scale manufacturing companies', South African Journal of Information Management 16(1), 593-603. https://doi.org/10.4102/sajim.v16i1.593

Razali, N.B.M., Mamun, A.A., Zakaria, M.N., Malarvizgi, C.A. \& Nawi, N.B.C., 2017 'Knowledge management system for decision centric for manufacturing SMEs: A conceptual framework', American Scientific Publishers 23, 2938-2941. https:// doi.org/10.1166/asl.2017.7612

Ribiere, V. \& Christian, W., 2013, '10 years of knowledge management theory and practices', Knowledge Management Research and Practice 11(1), 4-9. https://doi. org/10.1057/kmrp.2012.64

Salleh, S.M., Ismail, N.S., Hamazah, M.F.S., Zahari, M.S.A., Mohammed, H.N. \& Abdullah, N., 2017, 'Knowledge sharing and organizational commitment in organization', Journal of Applied Environmental Bio-Sciences 7(58), 37-40.

Santoro, G., Vrontis, D., Thrassou, A. \& Dezi, L., 2017, 'The internet of things: Building a knowledge management system for open innovation and capacity', Technological Forecasting \& Social Change March, 1-7. https://doi.org/10.1016/j. Technological Forecasting
techfore.2017.02.034

Shamim, S., Cang, S. \& Yu, H., 2017, 'Supervisory orientation, employee goal orientation, and knowledge management among front line hotel employees', International Journal of Hospitality Management, 62, 21-32.
Sigala, M. \& Chalkiti, K., 2015, 'Knowledge management, social media and employee creativity', International Journal of Hospitality Management 45, 44-58. https:// doi.org/10.1016/j.ijhm.2014.11.003

Sohrabi, S. \& Mirali, S.N., 2014, 'The interaction of explicit and tacit knowledge', in J. Rooney \& V. Murthy (eds.), Proceedings of the International Conference on Intellectual Capital, Knowledge Management \& Organizational Learning, Sydney, Australia, 6-7 November, 2014, pp. 363-369.

Stock, G.N. \& Greis, N.P., 2010, 'Absorptive capacity and new product development', The Journal of High Technology Management Research 12, 77-91. https://doi. org/10.1016/S1047-8310(00)00040-7

Suh, Y., You, J. \& Kim, P., 2013, 'The effect of innovation capabilities and experience on cross-border acquisition performance', Global Journal of Business Research 7(3), 59-74.

Sulistiyani, R. \& Harwiki, W., 2016, 'How SMEs build innovation capabilities based on knowledge sharing behavior? Phenomenological approach', Procedia - Social and Behavioral Sciences 219, 741-747. https://doi.org/10.1016/j.sbspro.2016.05.070

Suppiah, V. \& Sandu, M.S., 2011, 'Organizational culture's influence on tacit knowledge-sharing behaviour', Journal of Knowledge Management 15, 462-477. https://doi.org/10.1108/13673271111137439

Republic of South Africa, 2004, 'National Small Business Amendment Act', viewed 25 Nov. 2017, from https://www.thedti.gov.za/business_regulation/acts/small business_amendment_act.pdf

Teece, D.J., Pisano, G. \& Shuen, A., 1997, 'Dynamic capabilities and strategic management', Strategic. Management Journal 18(7), 509-533. https://doi. org/10.1002/(SICI)1097-0266(199708)18:7\%3C509::AID-SMJ882\%3E3.0.CO;2-Z

Valdez-Juárez, L.E., García-Pérez de Lema, D. \& Maldonado-Guzmán, G., 2016, 'Management of knowledge, innovation and performance in SMEs', Interdisciplinary Journal of Information, Knowledge, and Management 11, 141-176.

Valentim, L., Lisboa, J.V. \& Franco, M., 2015, 'Knowledge management practices and absorptive capacity in small and medium-sized enterprises: Is there really a linkage?', R \& D Management 46(4), 713-717.

Wang, M. \& Yang, T., 2016, 'Investigating the success of knowledge management: An empirical study of small- and medium-sized enterprises', Asia Pacific Management Review 21(2), 79-91. https://doi.org/10.1016/j.apmrv.2015.12.003

Wiid, J. \& Diggines, C., 2013, Marketing research, 2nd edn., Juta and Company Ltd, Cape Town.

Zheng, S., Zhang, W., Wu, X. \& Du, J., 2011, 'Knowledge-based dynamic capabilities and innovation in networked environments', Journal of Knowledge Management 15(6), 1035-1051. https://doi.org/10.1108/13673271111179352

Zhou, K.Z. \& Li, C.B., 2012, 'How knowledge affects radical innovation: Knowledge base, market knowledge acquisition, and internal knowledge sharing', Strategic Management Journal 33(9), 1090-1102. https://doi.org/10.1002/smj.1959 